\title{
Phalangeal Microgeodic Syndrome in a Patient with Systemic Lupus Erythematosus
}

\author{
Shota Kurushima ${ }^{1}$, Yoshiro Horai ${ }^{1,2}$, Ayuko Takatani ${ }^{1}$, Ayako Nishino ${ }^{1}$, Shin-ya Kawashiri ${ }^{1}$, \\ Kunihiro Ichinose ${ }^{1}$, Hideki Nakamura ${ }^{1}$ and Atsushi Kawakami ${ }^{1}$
}

\begin{abstract}
:
We herein report a woman in her 50s with systemic lupus erythematosus (SLE) who developed swelling and pain in her fingers; the symptoms were more prominent in winter. Magnetic resonance imaging (MRI) revealed bone edema in the phalanges of both hands, which was compatible with phalangeal microgeodic syndrome (PMS). This is the first reported case of PMS in a patient with SLE and suggests that performing MRI should be considered for patients with SLE in order to assess the nature of finger symptoms and signs more precisely.
\end{abstract}

Key words: magnetic resonance imaging, phalangeal microgeodic syndrome, systemic lupus erythematosus

(Intern Med 56: 3385-3387, 2017)

(DOI: 10.2169/internalmedicine.9195-17)

\section{Introduction}

Phalangeal microgeodic syndrome (PMS), first reported by Maroteaux (1), is a disease characterized by pain and swelling in the fingers provoked by cold temperature. Systemic lupus erythematosus (SLE) is an autoimmune disease of unknown origin characterized by various skin symptoms, organ dysfunctions and the presence of serum autoantibodies. Although SLE often provokes frostbite-like symptoms and clinical signs in the fingers, to date, there have been no reports describing the co-existence of PMS and SLE. In this report, we describe a case of PMS diagnosed by magnetic resonance imaging (MRI) in an adult woman with SLE.

\section{Case Report}

A woman in her 50s was referred to our department in the winter with generalized pain in her fingers that was not limited to the joints along with mucocutaneous symptoms. She had a history of right radius fracture and arthroscopic hip reconstruction due to an injury of the articular surface of the hip. While under the care of the orthopedic department, her serum antinuclear antibody (ANA) titer was found to be elevated ( $\times 160$, homogenous pattern). At that time, however, she did not the meet criteria for a diagnosis of SLE, as she had no symptoms other than arthralgia. A physical examination on assessment at our department identified oral ulceration, alopecia, and swelling in her fingers. The results of subsequent laboratory investigations showed neither leukocytopenia nor renal dysfunction, serum C-reactive protein concentration and erythrocyte sedimentation rate within normal limits and no evidence of proteinuria or occult hematuria. A microscopic examination of the urine sediment did not reveal any erythrocytes, leukocytes or cellular casts. A serum autoantibody screen was positive for anti-double-stranded DNA antibody (concentration $27.4 \mathrm{U} / \mathrm{mL}$ ) but negative for anti-ribonucleoprotein antibody, anti-Sm antibody, anti-Scl70 antibody, anti-centromere antibody, anti-cardiolipin IgG antibody, lupus anticoagulant (measured by dilute Russell's viper venom time), rheumatoid factor and anti-citrullinated protein antibody (Table). The diagnosis of SLE was established by the presence of oral ulceration, alopecia and the detection of anti-double-stranded DNA and ANA, meeting four of the Systemic Lupus International Collaborating Clinics Classification criteria for SLE (2). Although finger X-ray

\footnotetext{
${ }^{1}$ Department of Immunology and Rheumatology, Division of Advanced Preventive Medical Sciences, Nagasaki University Graduate School of Biomedical Sciences, Japan and ${ }^{2}$ Department of Rheumatology, Clinical Research Center, National Hospital Organization Nagasaki Medical Center, Japan

Received: March 17, 2017; Accepted: April 24, 2017; Advance Publication by J-STAGE: October 11, 2017

Correspondence to Dr. Yoshiro Horai, yoshirohorai0518@yahoo.co.jp
} 
Table. Laboratory Findings at the Referreal to Our Department.

\begin{tabular}{|c|c|c|c|c|c|c|c|}
\hline \multicolumn{6}{|c|}{$<$ Blood tests $>$} & \multicolumn{2}{|l|}{$<$ Urinalysis $>$} \\
\hline WBC & $4,800 / \mu \mathrm{L}$ & $\mathrm{TP}$ & $7.0 \mathrm{~g} / \mathrm{dL}$ & CRP & $0.02 \mathrm{mg} / \mathrm{dL}$ & Protein & negative \\
\hline Seg & $58 \%$ & Alb & $4.4 \mathrm{~g} / \mathrm{dL}$ & $\mathrm{IgG}$ & $1,283 \mathrm{mg} / \mathrm{dL}$ & Occult blood & negative \\
\hline Ly & $35 \%$ & T.Bil & $0.5 \mathrm{mg} / \mathrm{dL}$ & CH50 & $36.3 \mathrm{U} / \mathrm{mL}$ & $\mathrm{RBC}$ & $<1 / \mathrm{HPF}$ \\
\hline Mo & $4 \%$ & LDH & $140 \mathrm{IU} / \mathrm{L}$ & $\mathrm{C} 3$ & $89.3 \mathrm{mg} / \mathrm{dL}$ & WBC & $<1 / \mathrm{HPF}$ \\
\hline Eo & $2 \%$ & AST & $19 \mathrm{IU} / \mathrm{L}$ & $\mathrm{C} 4$ & $21.4 \mathrm{mg} / \mathrm{dL}$ & Cellular casts & negative \\
\hline $\mathrm{Ba}$ & $1 \%$ & ALT & $14 \mathrm{IU} / \mathrm{L}$ & anti-dsDNA Ab & $27.4 \mathrm{U} / \mathrm{mL}$ & & \\
\hline $\mathrm{RBC}$ & $458 \times 10^{4} / \mu \mathrm{L}$ & $\gamma-\mathrm{GTP}$ & $11 \mathrm{IU} / \mathrm{L}$ & anti-RNP Ab & $2.1 \mathrm{U} / \mathrm{mL}$ & & \\
\hline $\mathrm{Hb}$ & $13.6 \mathrm{~g} / \mathrm{dL}$ & ALP & 199 IU/L & anti-Sm Ab & $0.5 \mathrm{U} / \mathrm{mL}$ & & \\
\hline $\mathrm{Ht}$ & $40.1 \%$ & $\mathrm{Na}$ & $143 \mathrm{mEq} / \mathrm{L}$ & anti-Scl-70 Ab & $5.5 \mathrm{U} / \mathrm{mL}$ & & \\
\hline \multirow[t]{2}{*}{ Plt } & $29.7 \times 10^{4} / \mu \mathrm{L}$ & $\mathrm{K}$ & $4.2 \mathrm{mEq} / \mathrm{L}$ & anti-centromere $\mathrm{Ab}$ & $<0.5 \mathrm{U} / \mathrm{mL}$ & & \\
\hline & & $\mathrm{Cl}$ & $109 \mathrm{mEq} / \mathrm{L}$ & anti-cardiolipin $\mathrm{Ab}$ & $2.3 \mathrm{U} / \mathrm{mL}$ & & \\
\hline \multirow[t]{3}{*}{ ESR } & $8 \mathrm{~mm} / \mathrm{hr}$ & $\mathrm{Ca}$ & $9.5 \mathrm{mg} / \mathrm{dL}$ & LAC(dRVVT) & 1.04 & & \\
\hline & & BUN & $9 \mathrm{mg} / \mathrm{dL}$ & $\mathrm{RF}$ & $7.9 \mathrm{U} / \mathrm{mL}$ & & \\
\hline & & $\mathrm{Cr}$ & $0.58 \mathrm{mg} / \mathrm{dL}$ & anti-CCP Ab & $0.3 \mathrm{U} / \mathrm{mL}$ & & \\
\hline
\end{tabular}

Ab: antibody, Alb: albumin, ALT: alanine transaminase, ALP: alkaline phosphatase, AST: aspartate transaminase, BUN: blood urea nitrogen, CRP: C-reactive protein, ESR: erythrocyte sedimentation rate, Hb: hemoglobin, HPF: high-power field, Ht: hematocrit, IgG: immunoglobulin G, LAC (dRVVT): lupus anticoagulant (dilute Russell's viper venom time), LDH: lactate dehydrogenase, PLT: platelet count, RBC: red blood cell count, T. Bil: total bilirubin, TP: total protein, WBC: white blood cell count, $\gamma$-GTP: $\gamma$-glutamyl transpeptidase

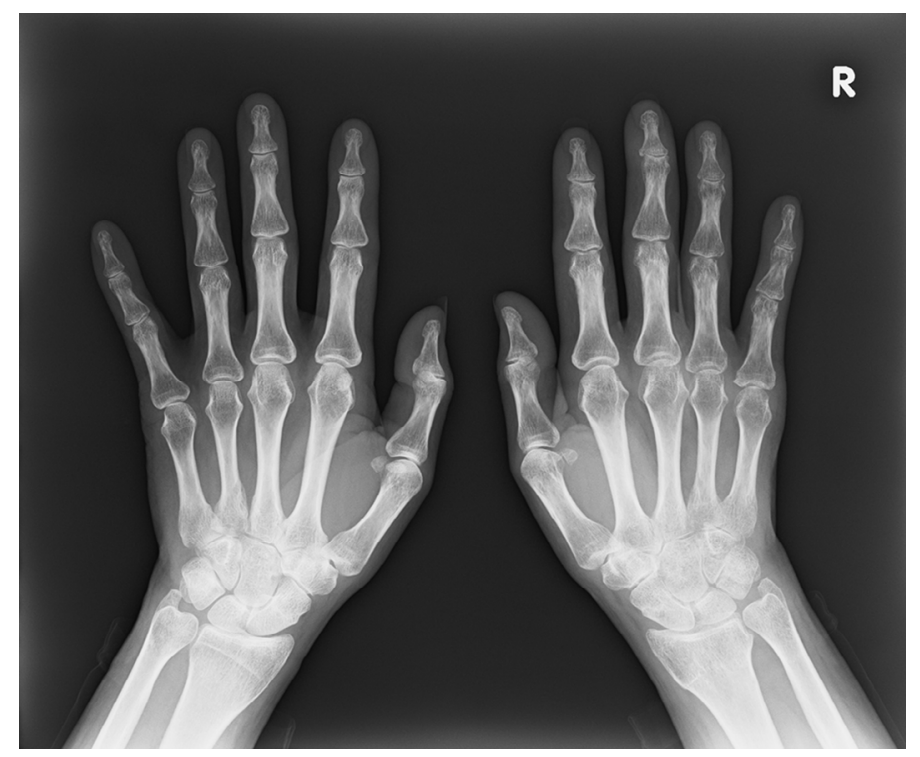

Figure 1. Hand X-ray findings. No abnormalities were identified on the bone surfaces or diaphyses.

showed no abnormality of the bone surfaces or diaphyses (Fig. 1), MRI-short inversion time inversion recovery (STIR) revealed diffuse high signal intensity in the bone marrow of her metacarpals and phalanges in both hands, findings that are characteristic of PMS. There was no evidence of synovitis or tenosynovitis on the STIR images that would have explained the cause of her finger manifestations (Fig. 2). We advised her to avoid low temperatures and elected not to initiate glucocorticoid therapy due to the lack of any evidence of active disease.

\section{Discussion}

The pathophysiology of PMS, the physical manifestations of which are similar to frostbite, is considered to be disturbance of the peripheral circulation caused by cold temperature (3). Although PMS mainly affects children (1), some adult cases have been reported $(4,5)$. The disorder is named after its typical X-ray findings, with a 'microgeode' being a small osteolytic lesion in the case of PMS in the diaphysis of a phalanx (6). However, these X-ray findings may not always be apparent (4), as in our case. The characteristic MRI findings have been described as low T1 signal intensity and 
A.

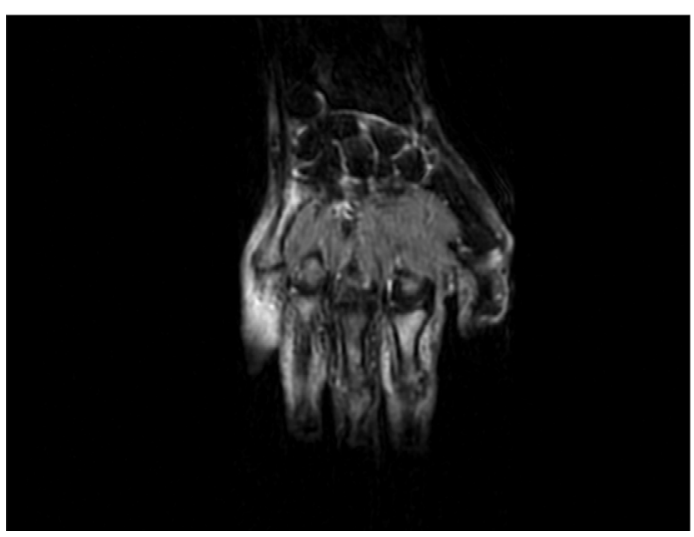

B.

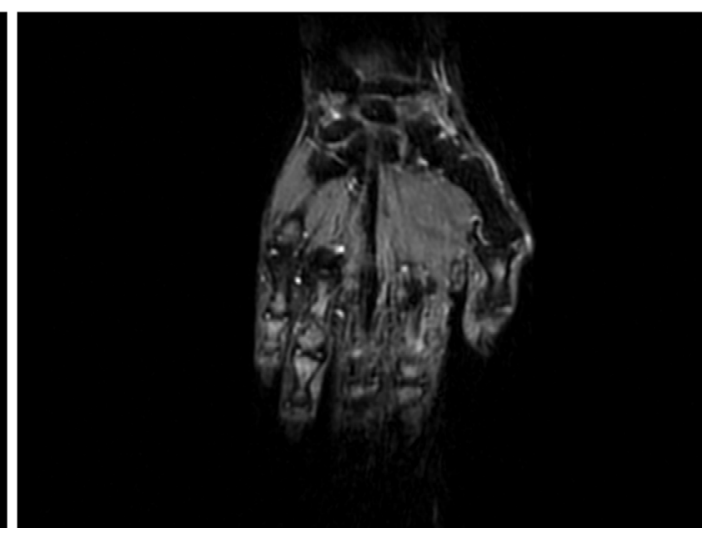

Figure 2. Hand MRI-short inversion time inversion recovery. Diffuse high signal intensity was evident in the bone marrow of the metacarpals and phalanges of both hands. A: Right hand. B: Left hand.

high STIR signal intensity in the phalanges (7), which are considered to reflect bone edema. MRI is reportedly capable of detecting PMS when there are no X-ray findings, yielding high sensitivity without exposure to ionizing radiation (4).

Although SLE may be complicated by abnormalities of the peripheral circulation, including Raynaud's phenomenon (RP) and articular manifestations (8), which may also be found in PMS, there have been no previous reports of PMS in a patient with SLE. In our case, there was no evidence of RP, and MRI revealed neither synovitis nor tenosynovitis. We therefore decided that our patient's symptoms were due to PMS. We recommend that MRI be considered for patients with SLE and finger symptoms and signs, as a PMS diagnosis may avoid unnecessary treatment, since the symptoms of PMS resolve spontaneously within six months in most cases (3). Musculoskeletal ultrasound (US) is widely used to detect bone erosion and synovitis in rheumatoid arthritis at an early stage with high sensitivity. However, the effectiveness of US for diagnosing PMS is unclear, as there have been no reports describing the US findings in PMS. Future investigations will be required in order to assess the effectiveness of US for a PMS diagnosis.

We encountered a patient with SLE complicated by PMS detected by MRI. Physicians should be aware that peripheral finger swelling and pain may be caused by PMS in patients with SLE and that MRI is a reliable means of detecting PMS and excluding other differential diagnoses.
The authors state that they have no Conflict of Interest (COI).

\section{References}

1. Maroteaux P. 5 cases of microgeodic disease of phalanges of unknown etiology in infants. Ann Radiol (Paris) 13: 229-236, 1970.

2. Petri M, Orbai AM, Alarcon GS, et al. Derivation and validation of the Systemic Lupus International Collaborating Clinics classification criteria for systemic lupus erythematosus. Arthritis Rheum 64: 2677-2686, 2012.

3. Inoue G, Miura T. Microgeodic disease affecting the hands and feet of children. J Pediatr Orthop 11: 59-63, 1991.

4. Nishino A, Kawashiri SY, Nakashima Y, et al. Two rare cases of adult-onset phalangeal microgeodic syndrome with magnetic resonance imaging-proven bone edema transiently occurring in winter. Joint Bone Spine 80: 523-524, 2013.

5. Sato K, Sugiura H, Aoki M. Transient phalangeal osteolysis (microgeodic disease). Report of a case involving the foot. J Bone Joint Surg Am 77: 1888-1890, 1995.

6. Meller Y, Bar-Ziv J, Goldstein J, et al. Phalangeal microgeodic syndrome in childhood. A case report. Acta Orthop Scand 53: 553-556, 1982.

7. Fujita A, Sugimoto H, Kikkawa I, et al. Phalangeal microgeodic syndrome: findings on MR imaging. AJR Am J Roentgenol 173: 711-712, 1999.

8. Bhatt SP, Handa R, Gulati GS, et al. Peripheral vascular disease in systemic lupus erythematosus. Lupus 16: 720-723, 2007.

The Internal Medicine is an Open Access article distributed under the Creative Commons Attribution-NonCommercial-NoDerivatives 4.0 International License. To view the details of this license, please visit (https://creativecommons.org/licenses/ by-nc-nd/4.0/).

(C) 2017 The Japanese Society of Internal Medicine Intern Med 56: 3385-3387, 2017 